\title{
PERCEPCÕ̃S DE CASAIS HETEROSSEXUAIS ACERCA DO USO DA CAMISINHA FEMININA
}

\author{
Heterosexual couples perception about the using of female condom \\ Percepciones de parej as heterosexuales acerca del uso del preservativo femenino
}

Vera Lúcia de Oliveira Gomes ${ }^{1}$

Adriana Dora da Fonseca

Maria da Graça Jundi ${ }^{3}$

Tarsila Piveta Severo ${ }^{4}$

\section{RESUMO}

Objetivou-se, nesta pesquisa exploratório-descritiva, qualitativa, conhecer as percepções de casais heterossexuais jovens, acerca do uso da camisinha feminina e compreender os fatores que propiciam e dificultam seu uso rotineiro. Coletaram-se os dados em outubro e novembro de 2007, por meio de questionário autoaplicável. Utilizou-se o Discurso do Sujeito Coletivo na análise. A idade dos 26 informantes variou entre 20 e 27 anos. Apreendeu-se que conhecem a eficiência desse método, mas reconhecem a dificuldade das mulheres para a negociação. Como limitantes apresentam pequena divulgação e alto custo. Do ato sexual protegido por camisinha feminina emergiram depoimentos discordantes. Uns enfocam o desconforto, dor e aparência grotesca, outros abordam a praticidade, confiabilidade e prazer; no entanto, salientam que a falta de familiaridade e 0 desconhecimento são fatores que desencadeiam grande parte das dificuldades, evidenciando, assim, a necessidade de implementação de novas estratégias de educação em saúde.

Palavras-chave: Saúde da Mulher. Educação em Saúde. Doenças Sexualmente Transmissíveis

\begin{abstract}
This descriptive exploratory, qualitative, research was aimed to know the perception of young heterosexual couples, relating to the use of female condoms and understand the factors that propitiate and make difficult its routine use. The data had been collected in October and November of 2007, through selfadministered survey. The Discourse of the Collective Subject was used in the analysis. The age of the 26 informants vary from 20 to 27 years. It had been learned that they know the efficiency of this method, but they recognize the difficulty of women to the negotiation. As limitations to the use they express the low and the high cost. From the sexual relation protected by female condom emerged conflicting statements. Some focus on the discomfort, pain and grotesque appearance, others approach the practicality, reliability and pleasure, however they stress that the lack of familiarity and knowledge are factors that trigger many of the difficulties, evidencing the necessity of implement new strategies of health education.
\end{abstract}

Keywords: Women's Health. Health Education. Sexually Transmitted Diseases

\section{Resumen}

Esta pesquisa exploratoria-descriptiva, cualitativa, tuvo como objetivo conocer las percepciones de parejas heterosexuales jóvenes acerca del uso del preservativo femenino y comprender los factores que proporcionan y dificultan su uso rutinario. Los datos fueron recogidos en octubre y noviembre de 2007 a través de cuestionario autoaplicable. Fue utilizado el Discurso del Sujeto Colectivo en el análisis. La edad de los/as 26 informantes ha variado entre 20 y 27 años. Se ha aprehendido que conocen la eficiencia de ese método, pero reconocen la dificultad de las mujeres para la negociación. Como limitantes presentan pequeña divulgación y alto costo. Del ato sexual protegido por preservativo femenino emergieron testimonios discordantes. Unos enfocan la incomodidad, dolor y apariencia grotesca, otros abordan la practicidad, confiabilidad y placer, sin embargo resaltan que la falta de familiaridad y el desconocimiento son factores que desencadenan grande parte de las dificultades, evidenciando la necesidad de implementar nuevas estrategias de educación en salud.

Palabras clave: Salud de la mujer. Educación en salud. Enfermedades Sexualmente Transmisibles.

'Enfermeira. Doutora em Enfermagem. Professora Titular da Escola de Enfermagem da FURG. Tutora do Grupo PET/Enfermagem. Líder do Grupo de Estudos e Pesquisas sobre Enfermagem, Gênero e Sociedade - GEPEGS. Rio Grande-RS. Brasil. E-mail: vlogomes@terra.com.br, Enfermeira. Doutora em Enfermagem. Professora Adjunto e Diretora da Escola Enfermagem da FURG. Líder do Grupo do - GEPEGS. Rio Grande-RS. Brasil. E-mail: adriana@vetorial.net, ${ }^{3}$ Enfermeira. MSc pelo Programa de Pós-graduação em Enfermagem da FURG. Integrante do GEPEGS. Rio Grande-RS. Brasil. E-mail: graça_jundi@yahoo.com.br, ${ }^{4}$ Enfermeira pela FURG. Integrante do GEPEGS. Rio Grande-RS. Brasil. E-mail: tarsilasevero@yahoo.com.br 


\section{INTRODUÇÃO}

As Doenças Sexualmente Transmissíveis (DSTs) representam um grave problema de saúde pública, embora sua real magnitude permaneça ocultada, muitas vezes, pela automedicação, decorrente da falta ou ineficiência de ações educativas. Entre os fatores que contribuem de forma significativa para a exacerbação desse quadro, figuram o constrangimento, a deficiente abordagem por parte de profissionais de saúde equestões de gênero. ${ }^{1}$

Parafraseando Joan $\mathrm{Scott}^{2}$, uma das pioneiras nos estudos de gênero, esse termo remete ao fato de que uma informação sobre o assunto "mulheres" necessariamente implica informação sobre "homens", pois o estudo de um requer o estudo do outro, ou seja, "o mundo das mulheres faz parte do mundo dos homens"2:7. Assim, tais questões, culturalmente instituídas, indicam que no jogo da sedução, as mulheres precisam se "mostrar inexperientes e pouco predispostas ao sexo", 3:1060 enquanto que aos homens cabe o papel de tomar a iniciativa, de forma que, tradicionalmente, 0 ato sexual seja almejado pelos homens e consentido pelas mulheres. ${ }^{3}$ Essa passividade feminina, certamente, traz sérias implicações para a negociação do sexo seguro.

Segundo estimativas da Organização Mundial de Saúde, ocorrem 340 milhões de novos casos de DSTs curáveis no mundo a cada ano. ${ }^{4}$ No que se refere especificamente à Síndrome da Imunodeficiência Adquirida (AIDS), desde o surgimento do primeiro caso em 1980 até o final de junho de 2007, foram identificados no Brasil 474.273 casos. ${ }^{5}$ Essa síndrome, por sua elevada incidência, vem caracterizando-se como uma subepidemia. Dados divulgados pelo Boletim Epidemiológico Aids/DST indicam que, no ano de 2002, ela chegou a atingir 22,2 por 100 mil habitantes. Mesmo com uma discreta diminuição nessa taxa, os dados continuam alarmantes, pois em 2006 ocorreram 17,5 casos em cada 100 mil habitantes.

Inicialmente, acreditava-se que a AIDS seguiria um padrão de transmissão restrito aos "homossexuais masculinos, aos usuários de drogas injetáveis e às pessoas que recebiam transfusões de sangue, como os hemofílicos" "6:1. No entanto, ao longo da história, o perfil epidemiológico foi alterando-se, e, mesmo antes de completar uma década, a feminização da doença tornou-se uma realidade, constatada pela diminuição da proporção entre os casos notificados em homens e em mulheres.

Em 1983, quando foi diagnosticado o primeiro caso de AIDS em pessoa do sexo feminino, a razão entre homens e mulheres, acometidos pela síndrome, era de 40:1. Em 1986, já havia 15 homens para cada mulher com a doença, e em 2005 a cifra foi de 1,5:1, ou seja, a cada 15 homens havia 10 mulheres com AIDS 5 . Analisando-se, isoladamente, 0 aumento da incidência da doença entre as mulheres, a feminização da epidemia fica mais evidente. Enquanto em 1996 a incidência total era de 9,1 casos para 100 mil mulheres, em 2005 atingiu a cifra de 15,7. Além disso, nas mulheres com idade entre 30 e 49 anos, essa taxa supera 30 por $100 \mathrm{mil}^{5}$. Sabe-se ainda que, entre elas, a transmissão heterossexual é a predominante, atingindo no ano de 2007 o percentual de 94,9\%, enquanto que, entre os homens, essa via de transmissão representou $46,1 \%$.

Assim, as relações heterossexuais vêm constituindo a principal via de transmissão do HIV, pois cada vez mais as mulheres adquirem o vírus através do contato sexual com seus maridos ou companheiros. ${ }^{7: 749}$ Em consequência, a negociação do sexo seguro, até então vinculada quase que exclusivamente à prostituição, passou a ter um reconhecimento público e político como algo positivo, "a epidemia ultrapassou o tênue limite entre a imoralidade da rua e a segurança da casa, imiscuindo-se na sacralidade das relações conjugais". 9:21

Tal negociação precisa incluir o uso regular da camisinha, alternativa que, até o presente momento, constitui a única forma eficaz de evitar a transmissão do HIV por via sexual; no entanto, por envolver inúmeros aspectos socioculturais, essa discussão fica limitada a poucos casais, pois embora as mulheres tenham consciência de sua vulnerabilidade, elas sabem que "têm poder limitado para reduzir ou eliminar o risco em suas relações sexuais". 10:755

Cabe enfatizar que "a camisinha masculina é um método controlado pelos homens", 8:1310 o que pode justificar a dificuldade das mulheres para negociarem seu uso. Nesse sentido, a falta de autonomia feminina, advinda dos padrões culturais patriarcais, acrescida do controle da sexualidade e da desigualdade de gênero, são apenas alguns dos obstáculos. ${ }^{11}$

Estudo realizado junto a agentes comunitários de saúde na capital do Rio Grande do Sul evidencia que a abordagem do sexo seguro "assume contornos bem mais amplos do que os apresentados nos discursos oficiais de prevenção ao HIV/Aids" ${ }^{8: 1314} \mathrm{~A}$ iniciativa de negociação pode expor o público feminino a riscos mais imediatos que a relação sem preservativo, entre os quais destacam: a possibilidade de acusação de infidelidade; o risco de indiretamente estarem 
autorizando a infidelidade por parte do parceiro ou ainda de sofrerem agressão física. Pode-se dizer que, atualmente, as escravas do sexo são aquelas que o praticam por obrigação conjugal, medo, opressão e não por prazer. ${ }^{12}$

0 uso regular da camisinha masculina envolve uma série de valores impostos socialmente, como a reciprocidade de sentimentos e a lealdade, culturalmente implícita nos relacionamentos conjugais estáveis. Algumas mulheres não negociam por serem casadas, amarem seus companheiros e acreditarem na sua fidelidade. Outras, mesmo reconhecendo a infidelidade, não conseguem abordar o assunto temendo serem mal interpretadas ou acusadas de adultério. Seja qual for o motivo, um fato concreto é que as iniciativas governamentais, desenvolvidas pela Coordenação Nacional de DST/AIDS para conter a propagação da epidemia junto às mulheres, vêm apresentando resultados tímidos e insatisfatórios.

Uma das estratégias possíveis, para aumentar a eficácia dos programas de prevenção e controle das DSTs/AIDS, é a implementação e fortalecimento da "transversalidade de Gênero nas Políticas Públicas de Saúde no Brasil" 13:12. Nesse sentido, cabe salientar que as Políticas de Gênero diferenciam-se das Políticas para as Mulheres, enquanto as últimas enfatizam "a responsabilidade feminina pela reprodução social, pela educação dos filhos, pela demanda por creches, por saúde e outras necessidades que garantam a manutenção e permanência da família", 13:9 as políticas de gênero envolvem tanto a diferenciação dos processos de socialização de homens e mulheres quanto à natureza dos conflitos e das negociações que ocorrem nas relações interpessoais. Essa política deve buscar a superação das assimetrias de gênero, incentivando o empoderamento e autonomia feminina. ${ }^{13}$

Analisando-se os programas de prevenção às DSTs/AIDS, sob essa ótica, percebe-se um maior investimento de recursos e ações educativas direcionadas à população masculina. A distribuição gratuita, e em larga escala, do preservativo masculino é uma realidade em todo o território nacional. A divulgação de seu uso vem ocorrendo de forma sistemática pela mídia. Além disso, campanhas em datas especiais como carnaval, dia dos namorados e dia nacional de combate à AIDS, mantêm como ponto alto a distribuição de preservativos masculinos, acrescida de informações detalhadas acerca da sua conservação, transporte e uso. Pode-se inferir que é muito difícil um(a) pré-adolescente e até mesmo uma criança não saber a função de um preservativo masculino, e quase impossível não conhecê-lo.

Além disso, no meio científico, incontáveis são as pesquisas, com as mais diferenciadas amostras e abordagens, que procuram fomentar essa forma de prevenção. Obviamente tais condutas são pertinentes, precisam ser mantidas e até intensificadas. Estudos quali e quantitativos precisam ser realizados com 0 intuito de avaliar a eficácia desses programas e direcionar de forma mais efetiva tanto o desenvolvimento de ações educativas quanto a elaboração e implementação de Políticas Públicas que propiciem maior autonomia feminina.

Por outro lado, muitos são os entraves à utilização da camisinha feminina. No coletivo, destacase sua quase nula divulgação, havendo mulheres que não a conhecem e outras que sequer ouviram falar acerca dessa possibilidade de prevenção; a distribuição nos postos de saúde, quando existe, está limitada às profissionais do sexo e às mulheres portadoras de HIV ou doentes de AIDS; a dificuldade de comercialização sob alegação de custo elevado e a impossibilidade de distribuição em campanhas e eventos. Assim, enquanto a camisinha masculina faz parte do cotidiano, servindo até mesmo de brinquedo para crianças e adolescentes que a manuseiam livremente, a camisinha feminina é racionada e escondida, de forma que a mulher fica privada do acesso a um método que poderia lhe dar autonomia de decisão. Todos esses fatores denotam a inexistência da transversalidade de gênero nesse setor.

Além de um eficiente método de contracepção e prevenção das DSTs/AIDS ${ }^{14}$, a camisinha feminina apresenta como vantagens a praticidade no uso, a viabilidade de colocação horas antes do contato sexual, a possibilidade de a mulher conhecer melhor sua própria anatomia, bem como suprir a falta de lubrificação vaginal comum na menopausa. No entanto, os maiores benefícios são a liberdade de escolha e a maior autonomia das mulheres, minimizando as dificuldades de negociação. Ainda, para os homens com ejaculação precoce ou ereção insuficiente, a camisinha feminina facilita, ou mesmo possibilita, a relação sexual.

Pressupondo que o desconhecimento acerca da correta utilização da camisinha feminina bem como de seus benefícios e dificuldades estejam inibindo seu uso em nível individual e dificultando sua adoção nos programas públicos de saúde, realizou-se este estudo com os objetivos de: conhecer as percepções de casais heterossexuais jovens acerca do uso da camisinha feminina e compreender os fatores que propiciam e dificultam seu uso rotineiro 


\section{PERCURSO METODOLÓGICO}

Trata-se de uma pesquisa exploratóriodescritiva, com abordagem qualitativa. Foram informantes acadêmicos do sexto e sétimo semestres de um Curso de Graduação em Enfermagem do extremo sul do país e seus(suas) parceiros(as). Com esta opção, procurou-se apreender aspectos referentes ao uso da camisinha feminina que não se limitassem ao desconhecimento anatômico da genitália e à dificuldade de colocação. Esse grupo, por seu grau de escolaridade, possibilitou ainda que os dados fossem colhidos de forma escrita, o que resguardou a privacidade dos participantes durante a coleta de dados, permitindo a livre expressão das sensações e sentimentos, em relação ao vivenciado. 0 critério para integrar a amostra foi apenas a concordância, por meio da assinatura do Termo de Consentimento Livre e Esclarecido. 0 projeto foi aprovado pelo Comitê de Ética em Pesquisa da Universidade Federal do Rio Grande RS, sob o No $76 /$ 2007.

Inicialmente, entregou-se a cada acadêmica(o) um envelope contendo uma camisinha feminina e dois questionários autoaplicáveis, um para si e outro para o(a) parceiro(a). 0 questionário continha questões referentes a dois momentos distintos, um antes e outro após um ato sexual protegido por camisinha feminina. No primeiro, procurou-se apreender a opinião dos informantes acerca da camisinha feminina, em um sentido geral, ou seja, o que ouviram falar, o que leram e o que vivenciaram antes da participação neste estudo. A segunda parte foi elaborada visando possibilitar a compreensão dos fatores que propiciaram e dificultaram o uso da camisinha feminina, sendo esta subdividida em: percepções acerca da colocação da camisinha, do transcurso da relação sexual com camisinha e da retirada da camisinha feminina. Após o preenchimento, os instrumentos foram entregues à pesquisadora em envelopes lacrados, que só foram abertos ao término de toda a coleta, para inviabilizar a identificação dos informantes. Os dados foram colhidos em outubro e novembro de 2007.

A análise foi realizada por meio do Discurso do Sujeito Coletivo (DSC). Essa técnica, à semelhança de um quebra-cabeça, busca reconstruir, com pedaços de discursos individuais, os discursos-síntese necessários para expressar um determinado modo de pensar ou um imaginário específico acerca de um fenômeno. ${ }^{15}$

\section{RESULTADOS E DISCUSSÕES}

Foram informantes 26 jovens com idades entre 20 e 27 anos. Eram acadêmicos do Curso de Enfermagem doze moças e um rapaz, que participaram do estudo juntamente com seus(sua) companheiros(a). Apenas uma moça havia usado camisinha feminina. Entre os rapazes, nenhum havia utilizado, três não a conheciam e um nem ouvira falar a respeito da camisinha feminina. Acredita-se que esse seja o motivo pelo qual os depoimentos tenham sido embasados no uso da camisinha masculina e exemplificados por meio de comparações entre ambas. Estudo semelhante realizado com 300 universitários do interior do estado de São Paulo constatou que apenas $1,6 \%$ dos participantes haviam utilizado a camisinha feminina em seus relacionamentos. ${ }^{7}$

Para a apresentação dos resultados, inicialmente procurou-se apreender opiniões gerais acerca desse método, não importando se era ou não conhecido.

\section{Percepções acerca da camisinha feminina}

Ideia central: a camisinha feminina tem aspectos positivos e negativos.

A camisinha feminina é um método seguro de prevenção das DSTs, Aids e gravidez, além disso, dá maior conforto aos homens e autonomia de escolha às mulheres, pois muitas delas sentem-se envergonhadas em andar com a masculina na bolsa e na hora $\mathrm{H}$ pedir que ele use. Há quem fale ainda, sobre a estimulante sensação que o anel externo provoca no clitóris. No entanto, a camisinha feminina é pouco conhecida e pouco usada, foi ao cursar a disciplina de assistência de enfermagem ao adolescente que aprendi sobre seu uso e suas vantagens. 0 problema é que ela é muito cara e antiestética. (Discurso feminino).

A camisinha feminina possui mais benefícios que a masculina, embora não seja tão romântica, discreta e prática; ela é uma alternativa eficiente de prevenção das DSTs, AIDS e gravidez. Pode ser a única opção para a mulher, quando o parceiro se recusa a utilizar a masculina, por isso deveria ser mais difundida. Acho que, por questões 
culturais, de costume mesmo, esteja sendo pouco usada. É necessária uma conscientização que pode ser trabalhada com ações de marketing. (Discurso Masculino).

À semelhança do divulgado em inúmeros trabalhos científicos ${ }^{5-11}$ há entre os informantes o conhecimento de que a camisinha feminina é um método eficiente de proteção das DSTs/AIDS e gravidez. Entretanto, reconhecem que as mulheres têm dificuldades para negociarem "com seus parceiros a adoção de medidas preventivas, pois a camisinha masculina é um método controlado por homens". 8:1309

Nesse sentido, o próprio avanço da epidemia entre as mulheres tem a ver com a desigualdade de poder que, tradicionalmente, organiza as relações de gênero em todas as dimensões sociais ${ }^{6}$ e repercute negativamente na qualidade de vida e saúde das mulheres. Assim, seja em nome da fidelidade conjugal, da falta de poder decisório ou em decorrência das relações desiguais de gênero, as mulheres não usam 0 preservativo em relacionamentos estáveis, apesar de conhecerem os riscos a que estão expostas ${ }^{7}$ : 755 .

Foram relatados, ainda, como fatores limitantes ao uso da camisinha feminina a pequena divulgação, o alto custo e as questões culturais que permeiam as percepções acerca desse método de prevenção. Acadêmicos de uma universidade privada, citaram a existência de alergia, a falta de domínio na colocação, desconfor to e diminuição na sensibilidade, além de evidenciarem que a recusa masculina ao preservativo ocorre com maior frequência com as parceiras estáveis ou esposas, parecendo que associam essa medida preventiva à relação com prostitutas. . $^{7756}$

Tais achados podem ser avaliados sob dois ângulos. Na maior parte dos países, sejam eles desenvolvidos ou não, "a equidade ainda é uma virtualidade, uma utopia, o que representa a dolorosa face da condição feminina, em pleno século XXI"13:15. Pode-se questionar também 0 despreparo e 0 desconhecimento profissional acerca da camisinha feminina. Estudo realizado com provedores de serviços de atenção à mulher em New York, aponta que "a conduta de profissionais de saúde é um dos fatores determinantes para a baixa adesão ao método. ${ }^{10: 141}$ Situação semelhante ocorre no Brasil onde "a formação de médicos e enfermeiros se restringe a aspectos biológicos da reprodução e contracepção, não valorizando o preparo ao lidar com os mitos, boatos e valores". ${ }^{13: 113}$

Os demais dados foram colhidos com base em uma relação sexual, protegida por camisinha feminina, com o objetivo de apreender as percepções referentes à colocação, transcurso da relação e retirada da camisinha feminina.

\section{Percepções acerca da colocação da camisinha feminina}

Embora a camisinha feminina possa ser colocada até oito horas antes do ato sexual, ${ }^{12}$ sete pessoas a colocaram com uma antecedência de até cinco minutos; duas, dez minutos; e as demais 15, 25, 30 e 40 minutos. Os depoimentos, nessa etapa, revelaram ideias centrais discordantes, o que requereu a construção de discursos que contemplassem aspectos positivos e negativos, apontados por homens e por mulheres.

Ideia central: a colocação da camisinha feminina é fácil.

A colocação causou estranheza por ser a primeira vez que utilizei a camisinha feminina, no entanto, embora seja desconfortável, é fácil, bem prática, e a grande vantagem é o tempo prévio de colocação que não quebra o clima. 0 que dificulta um pouco é apenas o excesso de lubrificante, que faz com que escorregue entre os dedos, mas nada que possa prejudicar a posição correta. (Discurso feminino)

Acompanhei a parceira durante a colocação da camisinha feminina, que ocorreu de forma prática e rápida, porém, por se tratar da primeira vez de ambos, surgiram dúvidas quanto à posição do anel interno. Uma vantagem desse preservativo é o fato de ser colocado horas antes da relação, o que não acontece com a masculina, que quebra o clima por ter que ser colocada na hora. (Discurso masculino).

Ideia central: a colocação da camisinha feminina é difícil.

Achei complicada em comparação com a masculina, devido ao fato de ser colocada 
internamente. Tive dificuldade de manter o anel interno em forma de oito e não consegui ter certeza de que estava na posição correta. É horrorosa, além disso, quebra o clima. (Discurso feminino)

A colocação da camisinha feminina é difícil e demorada, no entanto, como o novo é sempre estranho, é só se acostumar. A masculina, além de prática e discreta, permite que o casal coloque, preservando o clima da relação, o que não acontece com a feminina. (Discurso masculino).

Percebe-se que, tanto nos discursos que apontam aspectos positivos quanto naqueles que enfocam aspectos negativos, acerca da colocação da camisinha feminina, há o reconhecimento de que a falta de familiaridade com o método e o desconhecimento são fatores que levam ao estranhamento, desencadeando a maior parte das dificuldades. Como exemplo, a possibilidade de antecipar a colocação é relatada por alguns/algumas como uma grande vantagem, pois "não quebra o clima" da relação, e ignorada por outros. Estudo semelhante enfoca que a falta de intimidade com o corpo, comum entre as brasileiras, explica a dificuldade em manusear métodos de barreira. ${ }^{11}$ Por tratar-se de uma pesquisa realizada com estudantes do final do curso de enfermagem, acreditou-se que tais fatores não fossem interferir nos resultados o que evidencia "nossas ignorâncias a respeito da complexa sexualidade humana". 13:8 Na realidade, mesmo entre médicos e enfermeiros que trabalham em unidades de referência para DSTs/HIV, há um déficit de conhecimento sobre o preservativo, ${ }^{11}$ fato que certamente interfere na prestação de cuidados à comunidade.

\section{Percepções acerca do transcurso da relação sexual com camisinha feminina}

Quase todos os depoimentos abordam aspectos referentes à praticidade, aparência e confiabilidade da camisinha feminina durante a relação sexual. Assim, os discursos foram construídos contemplando tais características e, na apresentação, enfocaram-se as vantagens e as desvantagens citadas por mulheres e por homens.

Ideia central: percebi uma série de vantagens.
Inicialmente tive receio. A aparência não transmite muita confiança, a preocupação era com a possibilidade de sentir o anel interno durante a relação, mas isso não aconteceu, acredito que ficou bem encaixada no colo do útero, porque nem senti sua presença. De vez em quando eu tocava para me certificar que a borda não tinha entrado na vagina, pois tinha medo que ela saísse do lugar. Acho que é difícil confiar em um método que se usa pela primeira vez, mas a continuidade do uso pode me deixar tranquila. Após a relação sexual percebi sua total segurança, além de achá-la confortável, agradável, sem muita diferença da masculina, com a vantagem de que essa não quebra o clima. Acredito até que senti mais prazer. Meu parceiro também gostou de usá-la, pois na sua concepção ela "não aperta". Ele quis olhar como ficava externamente. Acredito que a maioria dos homens não ache visualmente atraente por uma questão de costume. No entanto, o melhor da camisinha feminina é que com ela a mulher consegue "impor" seu desejo de prevenção, sem discussões (Discurso Feminino).

A camisinha feminina é mais confortável, dá maior sensibilidade e liberdade. Ela causa sensações mais prazerosas que a masculina, pois diminui o atrito excessivo e lubrifica de forma suficiente o caminho, tornando bem mais fácil a penetração. Não sei se haveria mudança na sensação se ela fosse colocada mais do que 30 minutos antes da relação. Quanto à aparência, não acredito que cause desmotivação sexual, porém pode atrapalhar no sexo oral (Discurso masculino).

Esses discursos evidenciam que 0 desconhecimento e a falta de habilidade com o método geram medo e insegurança e que o diálogo entre 0 casal pode propiciar a formação de opinião, além de facilitar no momento de decidir sobre a adoção de práticas sexuais seguras. Nesse sentido, cabe enfatizar que "sem o convencimento mútuo, dificilmente se fará uso consistente de proteção". 9:11

Ideia central: as principais desvantagens da camisinha feminina são o desconforto, a dor e a aparência grotesca. 
Não gostei de usar, achei desconfortável. Embora meu parceiro tenha se mostrado bem disposto a experimentar, não consegui me sentir confortável. Além disso, não gostei da aparência, um pouco grosseira, feia, muito grande, o tamanho até assusta. Ela deveria ter tamanho semelhante ao da masculina. A camisinha feminina diminui a sensibilidade, é incômoda, principalmente pelo anel que fica externo à vagina. No fim da relação tive até um pouco de dor. Enfim, senti desprazer e ardência. Meu parceiro também não gostou muito, quase broxou, por isso decidimos continuar com a masculina. (Discurso feminino)

Notei uma sensível redução da sensibilidade da glande quanto à temperatura e ao movimento. Também notei a sensação de que o pênis não ia até o fim de seu curso. É horrível, sem prazer nenhum. Além disso, a camisinha feminina é feia e grotesca. Resumindo, para mim, no que se refere às sensações e prazeres, tanto faz a masculina ou a feminina, com certeza o melhor é sem camisinha. (Discurso masculino)

Os discursos enfocam o desconforto e a aparência assustadora e comparam a camisinha feminina com a masculina. Entretanto, fica evidente no depoimento masculino que, mesmo tendo conhecimentos sobre a necessidade e importância do uso de preservativos, muitos jovens optam por não usarem esses métodos. Cabe enfatizar que a divulgação de estratégias de prevenção não se propõe a substituir o preservativo masculino pelo feminino, "mas sim criar formas de intervenção que promovam a ampliação do leque de opções". 16:21

\section{Percepções acerca da retirada da camisinha feminina}

Houve discordância nos relatos sobre o momento da retirada da camisinha feminina, como se pode evidenciar nos discursos a seguir:

Ideia central: embora requeira cuidados, a retirada da camisinha feminina é fácil e prática.

A retirada foi ainda mais fácil e prática que a colocação, não representando nenhum risco. Basta um pouco de cuidado para evitar vazamento de líquido. Não tive problemas, o manuseio é simples. (Discurso feminino)

A retirada da camisinha feminina parece ser tão ou até mais fácil que a masculina, requer um pouco de cuidado para evitar que o sêmen derrame, porém a masculina pode furar e você corre o risco de lançar espermas em sua parceira e provocar uma gravidez. (Discurso masculino)

Ideia central: a retirada da camisinha feminina é difícil.

Foi um alívio quando retirei. Ela é estranha, acho que não estava bem colocada. Quando meu parceiro retirou o pênis, apesar de eu estar segurando as bordas, ela saiu junto. Na realidade, com a camisinha não houve problemas, nem vazamento do esperma durante a retirada, mas ela é horrorosa. (Discurso feminino)

A impressão que dá é que a masculina é mais fácil de retirar, embora haja o risco de vazar provocando uma gravidez. A feminina não tem este risco, mas percebi certo desconforto por parte da parceira. (Discurso masculino).

Esses discursos, à semelhança dos anteriores, demonstram que a falta de conhecimento e de familiaridade com o método, associado a mitos e preconceitos, contribuem para a formação de opiniões acerca da camisinha feminina como algo horroroso, desconfortável por parte de alguns/mas informantes.

Opinião semelhante foi encontrada junto a universitários de cursos sem afinidade com a área da saúde no interior de São Paulo. Para eles, o preservativo feminino é muito caro, fica antiestético e é difícil de colocar. ${ }^{7}$ Com relação a essa dificuldade, "sabe-se que culturalmente as mulheres latino-americanas não foram educadas para conhecer o próprio corpo, ou se tocar", daí a dificuldade para aderirem a essa forma de prevenção. 7:756

Questionados acerca da possibilidade do uso rotineiro da camisinha feminina, apenas duas mulheres e um homem responderam de forma afirmativa. Quatro mulheres e três homens abordam o alto custo como o fator limitante.

Ideia central: Eu usaria de forma rotineira a camisinha feminina. 
Eu usaria a camisinha feminina, pelo maior conforto, praticidade e segurança, além de não interferir no prazer. Acredito que se tivesse a oportunidade de usar novamente teria, ainda, maior facilidade de manuseio. Pena que é tão cara. Acho bacana ter mais esta possibilidade para variar e não perder no quesito proteção. (Discurso feminino)

A camisinha feminina é de muito fácil manuseio e, se usada corretamente, tem praticamente $100 \%$ de eficácia. 0 único inconveniente é o custo e a não disponibilização na rede pública. Se fossem analisados outros critérios como sensação, prazer ou desprazer, eu a utilizaria sim. Acho ainda que é necessário mais do que um uso para a adaptação total dos parceiros. (Discurso masculino)

Ideia central Eu não usaria a camisinha feminina.

A camisinha feminina é cara e de colocação mais difícil que a masculina. Só utilizaria se não houvesse outra opção, pois não gostei. Ela não é prática como a masculina. Além disso, me causou sangramento após a relação sexual. Outro aspecto que vale ressaltar é que o mercado sempre inova com texturas e aromas a camisinha masculina, deixando-a mais versátil para outras opções e no sexo oral. (Discurso feminino.)

A camisinha masculina, para mim é um método mais fácil e tem custos mais acessíveis. Além disso, feminina me causou desconforto durante a relação sexual e sangramento em minha parceira. Não vou usar nunca mais e acho que ninguém gostaria de usá-la, a não ser que não houvesse outra opção. Não é fácil de carregar é o acesso é mais difícil. (Discurso masculino).

Percebe-se que dos 26 informantes, apenas três adotariam rotineiramente a camisinha feminina se o preço fosse acessível. Estudando a continuidade do uso desse preservativo, o Departamento de Epidemiologia da Faculdade de Saúde Pública constatou, ao contrário do presente estudo, uma alta aceitabilidade inicial que decai em função do serviço em que as mulheres são atendidas e da frequência mensal das relações sexuais. Naquele estudo, ao final de um ano, apenas $14,4 \%$ das 2.469 mulheres investigadas ainda usavam o preservativo feminino, sendo que o tempo médio de uso foi de 3,55 meses. ${ }^{10}$ Esses dados apontam para a necessidade de implementação de novas estratégias de divulgação do método, com vistas a torná-lo uma alternativa desejável e de fácil acesso à promoção da saúde sexual e reprodutiva da população brasileira.

\section{CONSIDERAÇÕES FINAIS}

Com este estudo foi possível confirmar o pressuposto de que o desconhecimento acerca da correta utilização da camisinha feminina, bem como de seus benefícios e dificuldades, estão inibindo seu uso em nível individual e dificultando sua adoção nos programas públicos. Além disso, evidenciam que as Políticas Públicas de Saúde não contemplam a equidade de gênero, pois, enquanto a camisinha masculina é gratuitamente distribuída, divulgada, e seu uso ampla e minuciosamente discutido nos mais variados cenários, a feminina é desconhecida e causa estranheza até mesmo entre acadêmicos dos últimos semestres do curso de graduação em Enfermagem. Na realidade, esse dado só vem corroborar a percepção de que profissionais de saúde precisam ser mais bem preparados para a abordagem de questões referentes à sexualidade, inclusive às referentes à sua própria sexualidade.

Para a implementação da tão necessária e urgente equidade é indispensável que

- se identifiquem e problematizem os principais entraves ao uso da camisinha feminina, entre eles as dúvidas, preconceitos e acessibilidade;

- se elaborem e implementem programas de educação em saúde, de divulgação, de subsídio e de distribuição da camisinha feminina ;

- se proporcione aos acadêmicos de enfermagem e integrantes das equipes de saúde a utilização rotineira desse método de prevenção das DSTs/AIDS, por meio do acesso gratuito, pois a familiaridade minimiza 0 estranhamento e dá a vivência necessária a uma argumentação convincente.

Acredita-se que dos resultados desse estudo possa advir uma nova perspectiva para divulgação do uso da camisinha feminina, tanto entre mulheres sexualmente ativas quanto nos serviços públicos de saúde, com vistas a incluí-la entre os métodos disponibilizados gratuitamente. Só assim se estará contribuindo para 
minimizar as desigualdades de poder de negociação no que se refere à prevenção das DSTs/AIDS.

\section{REFERÊNCIAS}

1 Araújo MAL, Silveira CB. Vivências de mulheres com diagnóstico de Doença Sexualmente Transmissível - DTS. Esc Anna Nery 2007 set; 11(3): 479-86.

2 Scott J. Gênero: uma categoria útil de análise histórica. Educação e Realidade. 1990 jul; 16(2): 5-22.

3 Cordeiro F, Heilborn ML, Cabral CS, Moraes CL. Entre negociação e conflito: gênero e coerção sexual em três capitais brasileiras. Cienca Saude Cole. 2009 jul; 14(4): 1051-62.

4 World Heath Organization-WHO. Infecciones de transmisión sexual y otras infecciones del tracto reproductivo: una guía para la práctica básica. [on line] 2005; [citado 2008 ago 7]. Disponível em http:// www.acnur.org/biblioteca/pdf/5276.pdf.

5 Brasil. Temático - Jovens. Boletim epidemiológico AIDS/ DST. [on-line] $2007 \mathrm{dez}$; [citado 2008 mar 5]; 4(1): 6-11. Disponível em: http://www.aids.gov.br/sites/default/files/ Boletim2007_internet090108.pdf .

6 Cantarino C, Soryama P. Feminização traz desafios para prevenção da infecção. Com Ciência [on-line]; [citado 2007 maio 30]. Disponível em http://www.comciencia.br/ comciencia/handler.php? section $=8$ \&edicao $=13$ \&id $=113$.

7 Cano MAT, Zaia JE, Neves FRA, Neves LAS. 0 conhecimento de jovens universitários sobre AIDS e sua prevenção. Rev. Eletr. Enferm [on-line]. 2007; 9(3): 748-58. Disponível em: http://www.fen.ufg.br/revista/v9/n3/v9n3a14.htm

8 Oliveira DLLC, Meyer DE, Santos LHS, Wilhelms DM. A negociação do sexo seguro na TV: discurso de gênero nas falas de agentes comunitárias de saúde do Programa Saúde da Família de Porto Alegre, Rio Grande do Sul, Brasil. Cad. Saude Publica. 2004 set; 20(5): 1309-318.

9 Portugal MAL. Preservativos masculino e feminino: novas e velhas negociações [tese\}. Rio de Janeiro(RJ): Departamento de Endemias Samuel Pessoa/FOC, Escola Nacional de Saúde Pública, Fundação Osvaldo Cruz; 2003.
10 Kalckmann S, Farias N, Carvalheiro JR. Avaliação da continuidade de uso do preservativo feminino em usuárias do Sistema Único de Saúde em unidades da região metropolitana de São Paulo, Brasil. Rev. Bras. Epidemiol. [on-line] 2009; [citado 2010 maio 5]; 12(2): 132-42. Disponível em: http://www.scielo.br/pdf/rbepid/v12n2/ en_04.pdf

11 Oliveira NS, Moura ERF, Guedes TG, Almeida PC. Conhecimento e promoção do uso do preservativo feminino por profissionais de Unidades de Referência para DST/HIV de Fortaleza-CE: o preservativo feminino precisa sair da vitrine. Saude Soc. 2008; 17(1): 106-16.

12 Amaro STA. A questão da mulher e a Aids: novos olhares e novas tecnologias de prevenção. Saúde Soc. [on-line] 2005 maio/ago; [citado 2007 abr 2]; 14(2): 89-99. Disponível em: http://www.scielo.br/ scielo.php?script=sci_arttext $\&$ pid $=$ S010 04 12902005000200010 \&lng=en\&nrm=iso.

13 Bandeira L. Avançar na transversalidade da perspectiva de gênero nas políticas públicas. Brasília(DF): CEPAL; 2005.

14 Smit J, Beksinska M, Vijayakumar G, Mabude Z. Short-

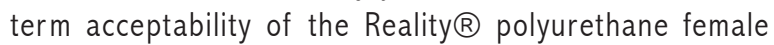
condom and a synthetic latex prototype: a randomized crossover trial among South African women. Contraception: an International Journal. 2006 Apr; 73(4): 394-98.

15 Lefèvre $F$, Lefèvre AMC. 0 discurso do sujeito coletivo: um novo enfoque em pesquisa qualitativa (desdobramentos). Caxias do Sul(RS): Educs; 2005.

16 Barbosa RM. HIV/AIDS, transmissão heterossexual e métodos de prevenção controlados pelas mulheres. Rio de Janeiro(RJ): ABIA; 2000. 